\title{
THE ROLE OF SOCIAL MEDIA IN IMPROVING THE ACADEMIC ENGLISH WRITING SKILLS OF ARAB STUDENTS
}

\author{
Ohood Kamel Ahmed Awadeh \\ Lecturer of English language at the \\ English Language Centre (ELC) of the \\ Arab American University of Palestine (AAUP)
}

\begin{abstract}
A striking feature of the $21^{\text {st }}$ century is the technological innovations that interfere in linguistic study and in social practices based on contemporaneity, especially, writing and reading. These social practices are the target of major revolutions from technology and electronic supports, which provided the creation of a range of communicative networks in the virtual world, establishing an infinite communicative link between different cultures and generations. The use of such platforms and the way reading is used might be an improvement tool for teaching English in Arab schools, associating its use in social networks and methodologies to guide the appropriate use for this new knowledge, for example, the use of media texts, since there is a change in society's behaviour with technological developments in seeking texts that can be read quickly and that bring complete information. Thinking about the interactive patterns emerging in cyber-culture sends our attention to social networks on the internet, which attract an increasing number of users and that is undeniably reflected in the offline reality. This research encourages deepening the studies about the students' experience with learning academic English writing skills through social media. To achieve the aim of this study, an exploratory descriptive study was developed, with a qualitative approach. The secondary data was used in the formation of this research. The online databases were the first priority of the researcher for data extraction as due to COVID-19, going to libraries was not possible. This research opens the door for new questions, bringing a priori the perspective for new field of research. The results from the research show that with critical theoretical material from several writers and extensive observation in favour of the use of social media in improving writing skills, it was noticed that there is a change in the way English is being perceived among Arab students, especially in the use of hypertext, the uses of social networks become a differentiating element in improving written English academic skills, if well applied in the didactic actions of writing.
\end{abstract}

Keywords: Academic English Writing Skills, Arab Students and Social Media Platforms

\section{INTRODUCTION}

\section{Background of the Study}

The conception of the students and their use of social networks is now understood as a process of improvement in which the students develop through coexistence with the new existing technologies. Anthropological formation, that is, the characterisation of society, resulting from the actions of the environment has been transforming the formation and improvement of the reader (Salloum, et al., 2018). It has transformed it into more critical and diversified society through the use of reading and writing, especially hypertexts, giving new forms to society interact with verbal and non-verbal texts (Alshabeb and Almaqrn, 2018). All this transformation is related especially to social media free of communication, digital platforms, social space in technological media that enable interaction, through written conversations, videos, images and audios as a literary source, mechanisms so present in teaching English language (Aloraini and Cardoso, 2018).

A striking feature of the $21^{\text {st }}$ century is the technological innovations that interfere in linguistic study and in social practices based on contemporaneity, especially writing and reading (Sharma, 2019). These social practices are the target of major revolutions from technology and electronic supports, which provided the creation of a range of communicative networks in the virtual world, establishing an infinite communicative link between different cultures and generations (Allam and Elyas, 2016). The techniques of production and reproduction of texts and the way they are made available make up some of 
the characteristics of this new society, based on new information technologies, activities with a computer or similar machines, where it provides training and manipulation of databases.

A conception in the way of life of the members of society in this century is the formation of communities for similar interests, and the relentless search for knowledge in an interactive and collective way, making the number of browsers on social networks increase every day, seeking to increase his social contact and his interest in quick and interpreted readings (AlGhamdi, 2018). The use of these texts and the way reading is used can be seen as an improvement tool for teaching English in Arab schools, associating its use in social networks and methodologies to guide the appropriate use for this new knowledge, for example, the use of media texts, since there is a change in society's behaviour with technological developments in seeking texts that can be read quickly and that bring complete information.

A number of researchers have observed the increasing number of people who use social networks all over the world, but with regard to written communication, has the use of these social networks positively influenced the development of these users' writing? This question was arisen to assess the role of social media in improving academic skills of students. Since the nature of this research is secondary, an extensive research was conducted including scholarly articles and journals. The main objective of this study is to understand how social networks have influenced the development of their users' writing. As secondary objectives, the research further explores how students have been behaving, regarding the quality of writing, given their conversations and posts on social networks and how educators have looked at this context coming from the use of new means of written communication, specifically from social networks.

In this context, the present work aims to explore the contribution of social media networks in teaching Arab students English academic writing skills. Moreover, the role of social media as a tool for improving Arab students' linguistic learning is also explored. However, in order to limit the focus of the study, the experience of only university going Arab students is explored. Amid the difficulties of the educational process, it is important to adopt new strategies that point to positive repercussions in expanding the scope of technological education, based on the objective of including sectors of new technologies (Alrasheedi, 2020). This inclusion is due both to the logic of use, and to the creation of opportunities, forms of use and innovations in the process of linguistic improvement and improvements (Alrabai, 2018).

One cannot deny the influence of social networks in the lives of a large part of the Saudi students. Knowing how to read and write, today, has become more important than it was in the days of yore, since almost everything in the virtual world requires knowledge of writing. However, many misunderstandings also occur due to insufficient knowledge of writing. On social media, most of the students abbreviate words and often make repeated mistakes without, however, realising those mistakes. But it is a fact that social networks, which are accessible to students these days by the different electronic devices that connect to the internet, have required students to write more, however this is not, one hundred percent, a sign of writing quality. This research sought to bring a broad view on how good the quality of writing of Arab university students who use the social networks.

\section{Research Question}

Do university students in the Arab world benefit from social media in improving their academic English writing skills?

\section{Aims and Objectives of the Study}

The aim of this study is to determine the role of social media platforms in improving the academic English writing skills of Arab university students. The objectives in this regard can be divided into the following:

- To determine the use of social media among Arab university students.

- To assess if social media is useful in improving English of Arab university students.

- To determine if the university encourages the Arab students to use social media as a platform for improving their written academic English skills. 


\section{LITERATURE REVIEW}

The technology as a means of storing information has provided humanity with great advances (Ahmed and Hassan, 2017). In this perspective, social media continues the evolution of social manifestations adopted by man over time through anthropology, cultural formation, in the construction of a new society, through rapid social dissemination and communicative ease (Salih and Elsaid, 2018). In this way, accessibility to reading engaged in the spelling process, are part of human development, the use of technology, broadens ideas and proposes interaction to improve life in society, as reading is an important link for the development of an entire society, and it is through it that man interacts and makes great achievements (Kutubkhanah, 2017).

According to a study by Aloraini, (2018) access to reading is part of social rights and plays an important role in the exercise of citizenship. Therefore, its relevance expands and integrates knowledge, opening more and more horizons of knowledge, enriching vocabulary and ease of communication, disciplining the mind and broadening consciousness (Pujiati and Tamela, 2019). The profile of the students has undergone major changes, especially in relation to the written material. This section presents the literature on the use of social media and how it assists students in improving their English academic skills.

It is understood with the systemic approach of Habes, et al., (2018) that the organism lives in a structural coupling with its environment, that is, it passes along its ontogenetic drift through a set of changes that the environment catalyses in its structure and vice versa, in a circular relationship and spiral (Al Khader, 2018). Within this understanding, Alqarni, Lally and Houston, (2019) consider that, on the one hand, daily life and ways of doing / living are affected by the emergence of technologies, as already discussed so far, users of any of these social objects will always modify them by making them unforeseen uses; re-signifying them through their daily practices (Alsharif and Limniou, 2020).

As Alfahadi, (2017) points out, the role of technologies in cultural changes is neither neutral nor omnipotent, rather they function as instruments whose meaning depends on the uses that social media users attribute to them, confirming that there is no way to separate things and techniques, from men, their values, their languages and culture (Alasfor, 2016). It is in this same perspective that Alharthy, Wang and Dudley, (2020) define cyber-culture as the result of the synergy between contemporary sociability and microelectronic technologies. He claims that the revolutionary potential of the computer network is not exactly in machines, but in the new modes of human interaction mediated by them. What moves the network is social interaction (Alsanosi, Alharbi and Alhebaishi, 2019) and this occurs through languages.

Thinking about the interactive patterns emerging in cyber-culture sends our attention to social networks on the internet, which attract an increasing number of users, which is undeniably reflected in the offline reality (Alshammari, 2020). Almarwaey and Lim, (2019) define social network as a set of interpersonal relationships that link individuals with mutual interests. Diverse interactional forms flow within social networks, in a dynamic process that transforms its structure. Networks "provide sociability, support, information, a sense of integration (Khatun and Al-Dhlan, 2017).

Despite being an old form of organisation, the network has taken on a new life with the internet. Social networks are made up of two main elements: social media platform users, who are the nodes in the network metaphor; and the connections established between them through the interaction that draw the structure of the network (Alasmari and Zhang, 2019). On the internet, the users are the profiles, or rather, the profiles are representations of the social media users. The ways in which social media users will represent themselves are constituted by social networking sites based on the resources offered by each of them, which in general vary according to the objective of the same (Alshenqeeti, 2018).

Facebook, for example, allows the user to post a profile picture, a cover image, add professional information such as a training institution and workplace, as well as indications of personal preferences, such as movies, music, books and television programs. Each action of users in this space, his postings, the interactions in which he gets involved contribute to his representation of the "me" 
(Alyoussef, Alamri and Al-Rahmi, 2020). Users continually make new posts, remove others and edit their profile (Alakrash, 2019). That is why representations are part of a process, in continuous construction. Having this awareness when dealing with the pedagogical appropriation of social networks is fundamental, because the activities proposed to students will be related to this profile built by him. Therefore, it is necessary to respect the limits of each student and the search for friendly solutions in cases of resistance.

While the users are the nodes of the network, the connections are constituted by the social ties formed from the interactions between these nodes. The interaction consists of exchanges between social media users, especially through the communication multiple languages. In educational networks, the purpose of interaction is to increase interest in constructive learning and to promote mutual support between students (Salloum, et al., 2018). The interactions will also happen through the different possibilities and limitations offered by the different social media platforms. Alshabeb and Almaqrn, (2018) thus define social media platforms as spaces that allow the articulation and visibility of dynamic, adaptive and self-organised networks and the maintenance of ties on the internet.

To have a sense of the success of these interactive environments, today not only Facebook is the most accessed social media platform, but Twitter and Instagram have also become popular. As perSharma, (2019) there are 76 million users of social media platforms in Saudi Arabia alone (Sharma, 2019). Different social media platforms are visited by 172 million people who spend about 4.7 billion minutes in the environment and update 532 million statuses - per day. 250 million photos are posted daily by users who, if they were developed or printed and stacked on top of each other, would reach the height of 80 Eiffel Towers (Allam and Elyas, 2016).

It is not irrelevant to point out that many educators and students make up these indexes. The school can no longer ignore the meanings that social networks have assumed in people's lives and is already beginning to realise that it is time to discover intelligent ways to take advantage of the interest that most students show in networks to teach them how to extract relevant ways of its use (AlGhamdi, 2018). In agreement with Alrasheedi, (2020), Alrabai, (2018) believe that the use of social networks, mediated by an educator, can be viable and minimise the paradoxical situation in which the school is inserted. Due to their eminently communicative and interactive character, where many languages flow, social networks on the internet have great potential for improving English language according to the pedagogy of multi-tools.

Taking advantage of the linguistic and cultural flow in social networks in favour of an English academic learning that is primarily interactive and attractive to Arab students is part of the undertaking. This action is undertaken by recommendation from university professors who have now started believing the power of social media in improving language of students (Ahmed and Hassan, 2017). Several foreign language teaching initiatives demonstrate that researchers have believed in the collaborative construction of knowledge through the pedagogical use of social networks to broaden students' interest in school. It favours the continuity of studies, horizontalize and positively narrow the relationship between teachers and students (Alasmari and Zhang, 2019) following the work developed by Salih and Elsaid, (2018).

Kutubkhanah, (2017) recommend the use of the social networking sites to teach the discipline "Interaction Through the Internet" which aimed at the development of the English written skills through collaborative tasks with the support of the resources available on these platforms. This experience proved the effectiveness of using the social networking platforms as an environment for complex learning, according to the needs of students and the objectives of the teacher of the discipline taught. At a university level, Aloraini, (2018) used Twitter as an open space to instigate Arab students to research based on recommendations from teacher-researchers, and the blog as an environment where students could organise and systematise information and productions, with space for colleagues' comments.

The integration of these platforms showed that it is important to include them not only to say 
that teachers use technologies, but to use them for the development of a network thinking to transform educational relationships. There was the development of computer skills, greater contact with the language, greater production in the language and pleasure in learning (Pujiati and Tamela, 2019).As a result of the work that conditioned at least one post on the site per day, most of the students involved found that communicating in English became easier after using Twitter, many also assessed that they felt less shy when communicating in the language, and only four or five students did not agree that Twitter had positive effects on communication in English (Habes, et al., 2018).

This number, the authors point out, was lower than that of students who did not effectively participate in the proposal by posting, which may indicate that some students attribute a theoretical value to the social media platforms. Al Khader, (2018) used Facebook as a complementary medium to the English classes given to students entering the Language course, like what Alqarni, Lally and Houston, (2019) did with Twitter. It aimed for studentsteachers to create teaching materials using various resources available on the network for written and oral production and make them available in the group created on Facebook. As disadvantages, Alsharif and Limniou, (2020) presented the participation of two classes in the same group, which acted as an inhibiting factor, and the difficulty in organising activities (posts) in the group. At the end of the semester, the experience was evaluated as positive by all students involved and considered valid and significant for the learning of the English language (Alfahadi, 2017).

In this work Alqarni, Lally and Houston, (2019) focused on the use of Facebook to motivate the learning of academic English writing skills, however the results from the research are exclusive to university students in Saudi Arabia. This is a relevant point in the selection of paths for this work. Still with regard to the choices made, Alsharif and Limniou, (2020) opted for a social media platforms for the purpose of learning English, through which students learn a language autonomously while carrying out teaching activities. Alsharif and Limniou, (2020) in this regard recommend using a platform that, in general, is familiar to students, as a way to awaken them to other potentialities of resources they already use.

\section{METHODOLOGY Introduction}

This research encourages deepening the studies about the students' experience with learning academic English writing skills through social media; therefore, the study takes into consideration the usual practices for their development, especially as an inseparable dimension of teaching as part of the conception of a tool for the educational principle (Kumar, 2019). In this sense, the proposed question in this study helped the researcher to configure a research path.

\section{Research Design}

To achieve the aim of this study, an exploratory descriptive study was developed, with a qualitative approach (Fletcher, 2017). The research is divided into stages where, a descriptive bibliographic survey was carried out to analyse the theme in published, online and printed studies, within the main databases in updated studies of the last 05 years (Mohajan, 2018).

\section{Data Collection}

The secondary data was used in the formation of this research. The online databases were given priority by the researcher for data extraction as due to COVID-19, going to libraries was not possible (Kumar, 2019). Due to similar reason, the researcher did not opt for primary data in this study. The databases of Science Direct, Scielo, PsychInfo and Google Scholar were used (Fletcher, 2017). The following keywords with Boolean 'AND' were used in the databases to collect the relevant articles and journals: academic writing English writing skills - social networks AND English writing - social networking ANDArab students - writing skills AND improved language - Arab students AND academic English writing.

\section{Data Analysis}

A critical analysis was carried out on the problem to analyse how Arab university students improve their written English academic skills through using social media. As a bibliographic survey was carried out, this study can be termed "state of knowledge". According to Mohajan, (2018) research known 
as "state of knowledge" is defined by the bibliographic character, they seem to bring together the challenge of mapping and discussing a certain academic production in different fields of knowledge, trying to answer what aspects and dimensions have been highlighted and privileged in different times and places, in what ways and under what conditions they have been produced and evaluated scientifically.

\section{DATA ANALYSIS \& DISCUSSION Findings}

There are several studies that have been carried out seeking the insertion of technology within the teaching of English language. In search for relevant studies to include in this article, a total of 10 articles and journals were identified. The following table shows those articles and journals along with the summaries of the findings. The data from only last five

Table 3: Secondary Sources Employed

\begin{tabular}{|c|c|}
\hline Authors & Summary of the Findings \\
\hline $\begin{array}{l}\text { Salloum, et } \\
\text { al., (2018) }\end{array}$ & $\begin{array}{l}\text { The notion of learning English involves the achievement of a goal, encouraged in the } \\
\text { social networking sites under the quantitative character, that is, the network values } \\
\text { the number of readers and, consequently, the number of readings and writing. }\end{array}$ \\
\hline $\begin{array}{l}\text { Alshabeb } \\
\text { and } \\
\text { Almaqrn, } \\
(2018)\end{array}$ & $\begin{array}{l}\text { In addition to bringing together groups with common interests, social media } \\
\text { platforms expanded spaces and participation in two different ways allowing students } \\
\text { who do not belong to certain groups to be exposed to genders and discourses adopted } \\
\text { by these groups, giving rise to gradual approaches and appropriations of such } \\
\text { genders and discourses. It allows barriers normally raised by factors such as gender, } \\
\text { race, age, physical appearance, economic class to be "hidden" in the virtual } \\
\text { environment, enabling greater contact and even interaction between social differences. }\end{array}$ \\
\hline $\begin{array}{l}\text { Aloraini and } \\
\text { Cardoso, } \\
\text { (2018) }\end{array}$ & $\begin{array}{l}\text { With interactivity, the written language has been delineated by informality, through } \\
\text { using images, abbreviations and compressed forms of the lexicon. However, users } \\
\text { who use online communication tools usually understand these writing conditions. }\end{array}$ \\
\hline $\begin{array}{l}\text { Sharma, } \\
\text { (2019) }\end{array}$ & $\begin{array}{l}\text { Writing has an expanded and unrelated approach to school and textual book, since it } \\
\text { is also present on digital platforms, where the students start to have a different role, } \\
\text { more participative and with an opportunity for expression. }\end{array}$ \\
\hline $\begin{array}{l}\text { Allam and } \\
\text { Elyas, (2016) }\end{array}$ & $\begin{array}{l}\text { The fears of some educators, that virtual language may interfere negatively with } \\
\text { conventional language, are unfounded; this also reinforces the fact that users of social } \\
\text { networks performed better on the textuality factors that must compose writing, } \\
\text { compared to non-users. }\end{array}$ \\
\hline $\begin{array}{l}\text { AlGhamd, } \\
(2018)\end{array}$ & $\begin{array}{l}\text { The defense is for these writings, as well as the supports that are used for this } \\
\text { purpose, such as social networks, for example, to be part of the classroom, and of the } \\
\text { school, to join forces for the construction of an individual and, consequently, of a more } \\
\text { critical and active society in which language practices are demanded. }\end{array}$ \\
\hline $\begin{array}{l}\text { Alrasheed, } \\
(2020)\end{array}$ & $\begin{array}{l}\text { While using social networks, students are exchanging ideas so that their critical } \\
\text { thinking skills will be improved. Social network services provide a better opportunity } \\
\text { for interaction, planning and obtaining more information with small reads. }\end{array}$ \\
\hline $\begin{array}{l}\text { Alrabai, } \\
(2018)\end{array}$ & $\begin{array}{l}\text { The use of textual genres, virtual genres and social networks enabled the development } \\
\text { of reading and writing practices based on individual and collective discussions, } \\
\text { reflections and textual production based on experiences lived by students in } \\
\text { environments increasingly used by students within the scope of social media } \\
\text { platforms. }\end{array}$ \\
\hline $\begin{array}{l}\text { Ahmed and } \\
\text { Hassan, } \\
\text { (2017) }\end{array}$ & $\begin{array}{l}\text { It is possible to promote development and foster student knowledge, in addition to } \\
\text { classes and program content. Using this, the tool in which they spend a significant } \\
\text { part of their time and with which they feel familiar: Facebook is making students } \\
\text { reflective and self-confident. }\end{array}$ \\
\hline $\begin{array}{l}\text { Salih and } \\
\text { Elsaid, (2018) }\end{array}$ & $\begin{array}{l}\text { Social media platforms are an efficient way to use a highly attractive language } \\
\text { learning tool for university students. }\end{array}$ \\
\hline
\end{tabular}


years is included to add the latest findings with the focus on improved academic English writing skills.

\section{Discussion of Findings}

Writing has become more agile and free, with a quantitative view, where it is possible to read various works quickly and under a critical eye (Salloum, et al., 2018). The media writer, increasingly critical, finds new ways of accessing it, since the speed at which information currently circulates, due to new technologies, is of textual formation and ultraexpandable diversity (Alshabeb and Almaqrn, 2018). On social media, writing becomes fast and surrounded by several "hyperlinks", which provide exposure to the intertextuality of the reader and he is obliged to be critical, clashes with new texts and authors from different cultures, as geographical borders almost do not exist in the virtual world (Aloraini and Cardoso, 2018). When writing, the student automatically exposes his ideas, suggests new texts, analyses different opinions, as a web of learning and exchange of knowledge. For Sharma, (2019), the cyberspace writer, having at his fingertips varied information in just a click of the mouse, easily goes to other texts when he realises that reading is monotonous and tiring, managing to associate an infinite number of texts to a same theme (Allam and Elyas, 2016). The sources of acquiring English writing skills and its interaction with human society is plausible, becoming an element present due to the way of use of time by modern society, distributing ease in its access (AlGhamdi, 2018). The use of the internet has made the current man a curious being, thirsty for information and quick knowledge. Another point to note is the use of writing, in social networks, spaces for mass communication, where written conversations, in audio and sharing of images, videos and documents of the most diverse themes are possible (Alrasheedi, 2020).

The rush for communication, makes students simplify words, forget functions, punctuation, grammatical rules become almost non-existent in the language, they transcribe the spoken language quickly, because their prey is to communicate. The use of renewed languages, with expanded forms of expression and communication, explains the intense use of social networks and platforms. For Alrabai, (2018) a new field expands, inducing educators to think about this new role for education, specifically for the school. This is because, it is not enough to simply put the old contents and the old ways of teaching in the new means of transmitting information to ensure that are being promoting changes in the educational system.

Technology combined with education has promoted great advances, especially in the writing process, as described by several authors in the research carried out, social networks allow students to interact and become more discursive (Ahmed and Hassan, 2017). It can be abstracted that social networks are an important tool for the development of the critical reader, who interprets and asks his questions. The opportunities provided by the internet for teaching are diverse. Discussions about how they can be used are just beginning, but what is already clear is that the internet is here to stay and is a tool that can no longer be ignored by researchers, teachers and educators (Ahmed and Hassan, 2017). According to Kutubkhanah (2017), communication is a necessity inherent to the human being, as well as food and physical comfort.

It is through communication that man begins to realise his potential and acquire or renew skills that allow greater and better action and interaction with the social world in which he is inserted (Aloraini, 2018). All transmission of knowledge, technological or not, happens through one form or another of teaching and this presupposes some type of communication, which must reflect an organised system that allows learning (Pujiati and Tamela, 2019). As learning something new, generally, presupposes the acquisition of new information, effective teaching cannot be considered that way, unless communication is also so. The writing process is something of a mediator, and its development can be seen in the different generations of mediators in the face of the technological revolution that involves the minds of readers in educational training.

\section{Theoretical Implications}

Teachers need to exercise the knowledge sharing and collaboration that students can provide on social media as part of their routine, investing in better technological environments, but mainly showing a spirit of 
building knowledge in groups (Habes, et al., 2018). For masters, access to social networks is a novelty far from their daily classroom reality, but for students, this communication process is part of their routine and becomes as attractive as a simple English language class based on books and oral conversation (Al Khader, 2018). Most teachers talk about the new technologies, which are of acceptability and practical utilitarian need. Active parts of the scholars in education seek to see this technology naturally, while others affirm that the social media platforms are necessary in Arab students' daily lives (Alqarni, Lally and Houston, 2019).

At the discursive level, new technology is accepted, but it is seen more as a necessary evil than a pleasure. They know it, but they still do not feel ready to use it. There is a relationship of strength between the speeches of the real need for technology, the willingness to participate and interact with it, and the pressure of the speeches that announce the change in education and survival of those who are inserted in the new context. The possibility of scientific and technological innovation demands changes in educational paradigms, requiring professionals to realise the urgency of "reformulating mentalities", according to a study by Alsharif and Limniou, (2020), that is, reforming thinking and fundamentals and recreating methods that insert technological bridges for the formation of individuals, making them contextualised with the world. Thus, there is a need to apply this knowledge, incorporating it into the students' reality in their learning process in the 21st century, challenging archaic education in the search for interaction with the contemporary world (Alfahadi, 2017). In the view of developing the various forms of intelligence, it is valid to use different resources in the teaching-learning process, resources that are more connected to the reality of this public, from which the school cannot remain distant (Alharthy, Wang and Dudley, 2020). The use of the internet by students is broader in social media - means of interaction by people through whom they share different types of texts - a space where it is possible to know, create and share knowledge.

\section{Managerial Implications}

To take advantage of texts found in the internet in the teaching-learning process, it must take into account that these, like other didactic resources, teachers need to have a guiding pedagogical proposal for their use to be effective in the process of building knowledge (Alsanosi, Alharbi and Alhebaishi, 2019). As it is still a didactic alternative, whose feasibility is being studied, there are also restrictions to be considered in relation to the educational use of social media. In this perspective, to bring improvements to teaching, a flowchart was drawn up showing the use of social networks and their insertion in teaching, relating the object of study and the actions that can be performed (Alshammari, 2020).

\section{LIMITATIONS OF THE STUDY}

The effectiveness of the students' literacy would lead them to a greater emancipation of their actions, understanding and performance in the world (Almarwaey and Lim, 2019). Thus, the new and prone forms of reading and writing to access the digital world directly influence students' daily lives, the form of interaction and the way of learning through using technological tools, such as the services provided by the web (Khatun and Al-Dhlan, 2017). The concept of a multi-literate individual appears as he can combine multiple skills, multicultural knowledge, behaviours appropriate to different contexts to exercise his rights and duties as a citizen in the present and in the future (Alasmari and Zhang, 2019). In this perspective, the new social context provided by electronic communication technologies, to exemplify, the computer and the Internet, start to contribute to the emergence of new social practices, unprecedented forms of communication and interaction which provide the creation of new textual / digital genres, such as blogs, wikis, pod-castings and Facebook as emerging technologies for learning.

\section{CONCLUSION}

It is known that there is no magic formula or ready recipe for using Social Media in Education, but because the network is a social space, it is also a space for education and learning, but it is the role of the teacher to explore the potential of this resource and of other technological tools with creativity. It seeks to propose activities that can be inserted in the context of their classes, but never forgetting that technology is a means and not an end. Teaching and learning today requires 
much more space-time, personal and group flexibility, less fixed content and more open research and communication processes. Given the range of electronic devices and ease of access to the internet, the concepts of improving English writing skills for Arab students existing in this current society were sought. With critical theoretical material from several writers and extensive observation in favour of the use of social media in improving writing skills, it has been noticed that there is a change in the way English is being perceived among Arab students, especially in the use of hypertext, the uses of social networks become a differentiating element in improving written English academic skills, if well applied in the didactic actions of writing. The value of acquiring knowledge and interacting with the world has been improved, since communication is the link between technology and knowledge through the massive innovation of information systems and the search for knowledge.

\section{FUTURE SCOPE}

Learning to use social networks in writing activities, in the education system, can be a mediating tool for the training of the Arab university students for improving their written English academic skills. It also facilitates the insertion in reading in the world of young people, since many young people spend hours of their day in a virtual space. The use of social networks is an open door to new literature and the construction of new texts. Thus, the results point to the need for teacher, student and technology (social media) interaction, inserting what may be valuable in the use of technology to transform reading into something that transmits pleasure and leads to the formation of new writers in the classroom. Experimenting and getting to know the new and inserting it into the traditional way of teaching are acts that expand learning. This research opens the door for new questions, bringing a priori the perspective for new field of research.

\section{REFERENCES}

Ahmed, S.S. and Hassan, A.Q., 2017. A Study on the Rationale of Social Media Use by the Students of King Khalid University. English Language Teaching, 10(8), pp.43-50.
Al Khader, K., 2018. A Cultural-historical Activity Theory Exploration into the Use of Social Media in Women's English Language Education in Saudi Arabia: Possibilities and Challenges (Doctoral dissertation, University of Manchester).

Alakrash, H., 2019. Motivation Towards the Application of ICT in English Language Learning Among Arab EFL Students. Alakrash, HM Razak, N, A. (2019). Motivation towards the application of ICT in english language learning among Arab EFL students. Journal of Advanced Research in Dynamical \& Control Systems, 11, pp.1197-1203.

Alasfor, K.A., 2016. Social media adoption among university instructors in Saudi Arabia.

Alasmari, T. and Zhang, K., 2019. Mobile learning technology acceptance in Saudi Arabian higher education: an extended framework and A mixed-method study. Education and Information Technologies, 24(3), pp.2127-2144.

Alfahadi, A., 2017. The Role of Social Media Sites in the Enhancement of English Language Learning at the University of Tabuk. International Journal of English and Education, 6(3), pp.105-113.

AlGhamdi, M.A., 2018. Arabic Learners' Preferences for Instagram English Lessons. English Language Teaching, 11(8), pp.103-110.

Alharthy, F., Wang, Y. and Dudley, A., 2020, July.An Analysis of the Current Policies for Social Media Use in Saudi Higher Education.In International Conference on Human-Computer Interaction (pp. 459470).Springer, Cham.

Allam, M. and Elyas, T., 2016.Perceptions of Using Social Media as an ELT Tool among EFL Teachers in the Saudi Context. English Language Teaching, 9(7), pp.1-9.

Almarwaey, A.O. and Lim, S.T., 2019. Informal Reasons for using Social Networking sites (SNSs) in learning English Language and Students' Self-Efficacy (SE).

Aloraini, N. and Cardoso, W., 2018. Social media in language learning: A mixedmethods investigation of Saudi students' perceptions. Future-Proof CALL: Language Learning as Exploration and 
Encounters-Short Papers from EUROCALL 2018, pp.1-5.

Aloraini, N., 2018. Investigating Instagram as an EFL learning tool. Arab World English Journal (AWEJ) Special Issue on CALL, (4).

Alrabai, F., 2018.Learning English in Saudi Arabia. English as a foreign language in Saudi Arabia: New insights into teaching and learning English, pp.102-119.

Alrasheedi, S., 2020. The Effect of Social Media Networking Use in EFL Classrooms in Saudi Arabia: An Argumentative Review. International Journal of English Linguistics, 10(1).

Alsanosi, A., Alharbi, A. and Alhebaishi, S., 2019. Smart Device Usage Frequency and Usage Level for Learning English. International Journal of Emerging Technologies in Learning (iJET), 14(19), pp.49-64.

Alshabeb, A. and Almaqrn, R., 2018. A study of EFL Saudi students' use of mobile social media applications for learning. Arab World English Journal (AWEJ) Special Issue on CALL, (4).

Alshammari, R., 2020. The Current Use of Mobile Devices among Students and Faculty in EFL Teaching in a Saudi Arabian Context. Turkish Online Journal of Educational Technology-TOJET, 19(2), pp.34-51.

Alsharif, M. and Limniou, M., 2020, July. Device and Social Media Usage in a Lecture Theatre in a Saudi Arabian University: Students' Views. In 7th European Conference on Social Media ECSM 2020 (p. 341).

Alshenqeeti, H., 2018. Technology in the language classroom: how social media is changing the way EFL is taught. Arab World English Journal (AWEJ) Special Issue on CALL, (4).

Alyoussef, I.Y., Alamri, M.M. and Al-Rahmi, W.M., 2020. Social Media Use (SMU) for Teaching and Learning in Saudi Arabia.

Fletcher, A.J., 2017. Applying critical realism in qualitative research: methodology meets method. International journal of social research methodology, 20(2), pp.181-194.
Habes, M., Alghizzawi, M., Khalaf, R., Salloum, S.A. and Ghani, M.A., 2018. The relationship between social media and academic performance: Facebook perspective. Int. J. Inf. Technol. Lang. Stud, 2(1), pp.12-18.

Khatun, A. and Al-Dhlan, K.A., 2017. Effectiveness of WhatsApp: A Social Media Tool for Student's Activities in Saudi Arabia. International Journal of Technology and Educational Marketing (IJTEM), 7(2), pp.17-23.

Kumar, R., 2019. Research methodology: A step-by-step guide for beginners. Sage Publications Limited.

KutubkhanahAlsaied, H.I., 2017. Perceived effectiveness of social media as an English language learning tool. Arab World English Journal (AWEJ), 8(1), pp.79-93.

Mohajan, H.K., 2018. Qualitative research methodology in social sciences and related subjects. Journal of Economic Development, Environment and People, 7(1), pp.23-48.

Pujiati, H. and Tamela, E., 2019, August.The Use of Instagram to Increase Students' Motivation and Students' Competence in Learning English.In 1st International Conference on Education Social Sciences and Humanities (ICESSHum 2019).Atlantis Press.

Salih, A.A.A. and Elsaid, A.S., 2018. Students Attitude Towards the Use of Social Media for Learning Purposes (Case Study: AlBaha University, College of Sciences \& Arts-Biljurashi). Journal of Literature, Language and Linguistics, 50, p.7.

Salloum, S.A., Maqableh, W., Mhamdi, C., Al Kurdi, B. and Shaalan, K., 2018.Studying the social media adoption by university students in the United Arab Emirates. International Journal of Information Technology and Language Studies, 2(3), pp.83-95.

Sharma, V., 2019.Saudi Students' Perspective on Social Media Usage to Promote EFL Learning. Online Submission, 2(1), pp. 129-139. 